\begin{abstract}
Iranica
Abstracta Iranica Revue bibliographique pour le domaine irano-aryen

Volume 42-43 | 2021

Comptes rendus des publications de 2019-2020
\end{abstract}

\title{
Christelle Jullien. « Les chrétiens en Iran sassanide »
}

Marie-Joseph Pierre

\section{OpenEdition}

1 Journals

\section{Édition électronique}

URL : https://journals.openedition.org/abstractairanica/51932

DOI : 10.4000/abstractairanica. 51932

ISSN : 1961-960X

Éditeur :

CNRS (UMR 7528 Mondes iraniens et indiens), Éditions de l'IFRI

Référence électronique

Marie-Joseph Pierre, «Christelle Jullien. « Les chrétiens en Iran sassanide » », Abstracta Iranica [En ligne], Volume 42-43 | 2021, document 2, mis en ligne le 30 décembre 2020, consulté le 24 décembre 2022. URL : http://journals.openedition.org/abstractairanica/51932 ; DOI : https://doi.org/10.4000/ abstractairanica. 51932

Ce document a été généré automatiquement le 24 décembre 2022.

Tous droits réservés 


\title{
Christelle Jullien. « Les chrétiens en Iran sassanide »
}

\author{
Marie-Joseph Pierre
}

\section{RÉFÉRENCE}

Christelle Jullien. « Les chrétiens en Iran sassanide » in Mohammad Ali Amir-Moezzi, Guillaume Dye (eds.), Le Coran des historiens. 3 vols. Paris : les Éditions du Cerf, 2019, vol. 1, p. 359-392

1 Cet ouvrage, résultat du travail d'une trentaine de chercheurs sur près de 4000 pages en 3 volumes, est désormais une référence incontournable pour qui veut aborder et comprendre l'histoire du Coran. Une introduction très détaillée s'appuie sur les données à la fois archéologiques, historiques, épigraphiques, codicologiques, relatives au milieu de composition du Coran et ses processus d'écriture. Les deux premiers tomes offrent un commentaire historique et philologique de chacune des sourates, au regard de l'ensemble des études effectuées alors, jusqu'aux études les plus actuelles. Le dernier volume comprend les références bibliographiques.

2 Le chapitre dévolu aux chrétiens en Iran sassanide s'intègre dans le tome 1, et participe à l'objectif de ce volume: dresser un tableau d'ensemble cherchant à mieux faire comprendre le milieu de genèse du corpus coranique. L'A. souligne que les communautés chrétiennes syriaques de l'empire iranien n'ont jamais constitué une culture dominante : mises au défi de l'intégration dans des milieux culturels et sociopolitiques non chrétiens, le monde mazdéen, que relaya le monde musulman. À l'arrivée de l'islam, elles sont marquées par la pluralité du fait de leurs choix doctrinaux, faisant suite aux grandes définitions conciliaires autour de la personne et de la nature du Christ. Une première partie porte sur les premiers indices d'une présence chrétienne et sur les traditions d'évangélisation. La littérature syriaque se fait l'écho des liens étroits entre milieu missionnaire et monde marchand laïc, support des initiatives de pénétration doctrinale. La seconde a trait aux déportations en Perse et 
leur incidence sur le développement des communautés sur le territoire. L'appropriation des savoir-faire était l'un des objectifs premiers de ces transferts de populations au cœur de l'empire. L'A. rappelle bien la mixité culturelle des communautés chrétiennes de Perse, reflet des sociétés en monde iranien. Les autres parties abordent la question des persécutions sous l'influence progressive du clergé mazdéen au sein des organes de pouvoir, et de la nécessaire loyauté politique des chrétiens en milieu mazdéen alors que les choix christologiques des Églises exacerbent les tensions de part et d'autre de la frontière. Après un éclairage bien synthétique sur l'organisation des communautés dyophysites et miaphysites en territoire iranien et la progressive évolution de l'Église syro-orientale vers l'autonomie, le thème des controverses inter-religieuses vient à propos éclairer les succès de l'implantation de l'islam, qu'expliquent sans nul doute les divisions internes des Églises notamment sur la question de la nature du Christ. Une partie a trait au rapport des élites avec le pouvoir ; l'A. souligne la profonde insertion des chrétiens dans les milieux politiques comme administratifs, et montre en parallèle comment l'écriture peut aussi devenir un moyen de défense communautaire (en revisitant par exemple le roi persécuteur en souverain favorable à la cause chrétienne, voire même christianisé, ou en dépeignant la supériorité du christianisme sur le mazdéisme - et bientôt sur l'islam). Les deux derniers sous-chapitres concernent le monachisme, qui donna aux Églises syriaques les atouts de leur prospérité et de leur dynamisme, spécialement en matière de missiologie, et la thématique du rôle - essentiel - joué par les chrétiens de Perse dans la transmission des savoirs, spécialement de l'héritage grec aux Arabes. Ce chapitre constitue un compendium particulièrement précis et utile pour connaître l'histoire des chrétiens dans l'empire iranien avant l'islam.

\section{AUTEURS}

\section{MARIE-JOSEPH PIERRE}

Directrice d'études honoraire, EPHE 